\title{
Evaluation of HEC-HMS Model for Water Resources Management in Maha Oya Basin in Sri Lanka
}

\author{
M.H.B.C.W. Herath and N.T.S. Wijesekera
}

\begin{abstract}
Water resources are being undergoing stress due to, increased water consumption resulting from rapid population growth, development activities, and industrialization for economic prosperity. Hence, sustainable water resources management is essential to fulfill the future requirements. The main challenge in this context is the unavailability of observed streamflow series. To develop a calibrated and validated hydrological model to address the prevailing condition is crucial with a proper understanding of catchment behaviour from the hydrological point of view. Therefore, water quantification with the aid of hydrological modeling is an essential requirement, to facilitate water resource management in ungauged watersheds. This work demonstrates the development of the HEC-HMS (Version 4.3) model to Giriulla catchment $\left(1,120 \mathrm{~km}^{2}\right)$ to facilitate the water resources management in the Maha Oya $\left(1,562 \mathrm{~km}^{2}\right)$ basin. To optimize the model performance RMSE was used as an objective function, while MRAE was used as a performance indicator. Further, visual performance evaluation was used, to check timing, high and low flow simulation capability. The developed HEC-HMS model was calibrated with over 75\% accuracy, while validated with $80 \%$ accuracy. The better performance during validation can be attributed to a better streamflow dataset that represents Thiessen averaged rainfall. The developed HEC-HMS model with its optimised parameters demonstrated that it can be utilised for water resources management in the Maha Oya basin.
\end{abstract}

Keywords: $\quad$ Hydrological Model, HEC-HMS, Calibration, Validation, Giriulla, Maha Oya

\section{Introduction}

From the time of ancient civilizations, mankind had been searching for water systems to fulfill their requirements. However, around the world, water has become scarce in quantity and poor in quality. This has been mainly due to increased water consumption resulting from rapid population growth, development activities, and industrialization for economic prosperity [1]. This situation is severely affected by impacts from anthropogenic climate change [2]. Hence, the difference between demand and supply of clean water is closing at a very rapid rate. As a result, systematic approaches are essential to develop the water resources at the local and national scale [3], to address the growing water resources scarcity, which causes difficulties when managing water.

Rainfall-Runoff models are very useful tools in this context [4] because they help to simulate the hydrological responses in the watersheds [5]. There are several hydrological models in use and they are HEC-HMS, SWAT, MIKE, SWMM etc. They consider various hydrological processes. The three main inputs other than topography used to describe and understand those processes are rainfall, streamflow, and evaporation. These models can be developed using various time resolutions including hourly, daily, monthly, seasonally, and annually. The common practice in the water resources planning and management sector is to develop rainfall-runoff models on a monthly scale [6], [7]. This is mainly because they are less data and parameter intensive when compared to the finer resolution models [8].

The main challenge in water resource development is the unavailability of adequate and reliable streamflow measurements. To develop a calibrated and validated hydrological model in order to address the prevailing

Eng. M.H.B.C.W. Herath, AMIESL, MSLNCOLD,

B.Sc. Eng. (Hons) (Moratuwa), M.Sc. Eng. (WREEM,

Moratuwa), Engineer, Mahaweli Authority of Sri Lanka.

Email:Chulani.herath@gmail.com

ORCID ID: https://orcid.org/0000-0003-1555-8173

Eng. (Prof.) N.T.S. Wijesekera, C.Eng., MIECE (UK),

FIE(SL), B.Sc. Eng.Hons (Peradeniya), PG Dip

(Moratuwa), M.Eng. (Tokyo), Ph.D(Tokyo), Senior

Professor, Department of Civil Engineering, University of

Moratuwa, Sri Lanka.

Email: sohanw2@gmail.com

ORCID ID: http://orcid.org/0000-0003-0964-4331 
condition is crucial with a proper understanding of catchment behaviour from the hydrological point of view. Therefore, water quantification with the aid of hydrological modeling is an essential requirement, to facilitate water resource management in ungauged watersheds.

Accordingly, Maha Oya Basin $\left(1,562 \mathrm{~km}^{2}\right)$ in the Western region of Sri Lanka was selected to carry out this study (Figure 1). 75\% of Maha Oya basin is located in the Wet Zone, while $25 \%$ of the basin lies in the intermediate zone of Sri Lanka. Further, it is the $11^{\text {th }}$ largest river basin in Sri Lanka, which has greater potential for water resources management. The main river is approximately $134 \mathrm{~km}$ long and it originates from the western part of hill country in Kandy and Kegalle districts, with elevations of $1,500 \mathrm{~m}$ MSL. The main river has 21 tributaries and Rambukkan Oya, Talagolla Oya, and Hingul Oya can be seen as the most contributory. The annual Thiessen average rainfall of the basin is approximately $2,219 \mathrm{~mm}$ and the average annual temperature is $26{ }^{\circ} \mathrm{C}$.

\section{Methodology}

\subsection{Gauging Stations and Data}

Giriulla Watershed was selected to investigate the applicability of the HEC-HMS model for water resources management in the Maha Oya basin. The hydro-meteorological stations were selected considering the spatial and temporal distribution of rainfall stations. These data were collected from the Department of Meteorology and the Department of Irrigation in Sri Lanka. In addition to that, land use data $(1: 50,000)$, contour data $(1: 10,000)$, and terrain data were collected from the Survey Department, Sri Lanka. Accordingly, five (05) rainfall stations, Aranayaka_Mini Hydro, Eraminigolla, Polgahawela, Ambepussa, and Andigama Farm were considered for the Giriulla watershed while Giriulla Gauging station considered as streamflow station. Makandura pan Evaporation station was considered as an evaporation station in this study (Figure 1). Daily data including precipitation, observed streamflow, and evaporation data were collected for a period of eighteen years, starting from 2000/2001 to 2018/2019 water year.

At the initial stage of data collection, all collected data were pre-processed and data checking was conducted including visual data checking, for the collected hydrometeorological data, to identify the data inconsistencies, outliers, and missing data etc. Moreover, Annual water balance (AWB) and the Double mass curves were used to identify the data inconsistencies. The rainfall station selection also follows the World Meteorological Organization (WMO) guideline by selecting the stations with less than $10 \%$ of missing data and station density greater than $575 \mathrm{~km}^{2} /$ station. The period of 2005/2006 to 2009/2010 was used as a calibration period, while the period of $2000 / 2001$ to $2003 / 2004$ was considered as validation period.

\subsubsection{Data Checking}

Sugawara et al. (1984) [9] had stated on the effectiveness in the use of weighted mean rainfall from several spatially distributed stations for accurate runoff analysis. Hence, Thiessen method was selected as the most appropriate catchment rainfall averaging method [10], [11], [12], [13], also because of its wide usage. Long-term average was used to gap-fill the Evaporation data.

Thiessen polygons drawn for Giriulla catchment are shown in Figure 1, while Thiessen weights are illustrated in the same Figure.

Visual data checking of Thiessen Average rainfall and streamflow in the daily time scale was performed to capture any incompatibilities in the rainfall and streamflow data. A similar comparison of individual rainfall and streamflow was performed to understand the spatial variability of rainfall at the selected gauging stations.

\subsection{Selection of Model and Objective Function}

Model selection greatly depends on the availability of data, the complication of the model development, and the purpose of the modeling [14]. However, water managers and planners prefer to work with models, which can handle lesser number of parameters and models with easy access to the modeling software. The HEC-HMS (version 4.3) model has been prioritized as the most appropriate model to carry out this research, since it is a freely available Physics-based model, and able to simulate with limited data available situations. Further, it is designed to model the rainfall-runoff processes of catchments in a wide range of geographical regions, such as large river basins and small urban or natural watersheds, all over the world including Sri Lanka [15], [16], [17]. 


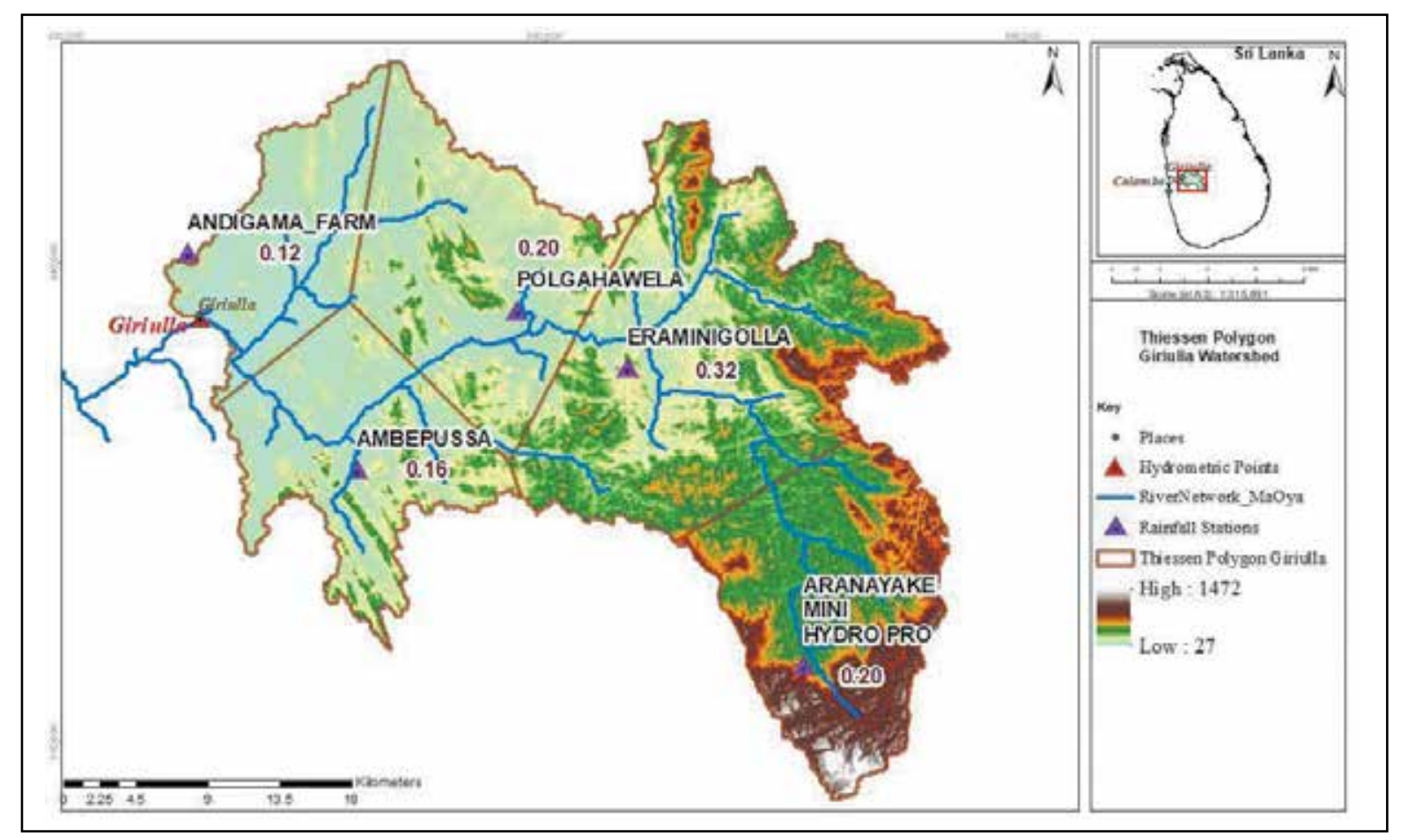

Figure 1 - Rainfall and Streamflow Stations, and Thiessen Weights of Giriulla Watershed

Based on literature, Root Mean Square Error (RMSE) was chosen as the Objective function for the current study (Equation 1). This was used to optimize the model performance and many studies have proven its suitability for use as an objective function in hydrological modeling [16], [17], [18]. The main objective of this study is to facilitate decision making for water resources management activities. In this, high flows representing floods and low flows representing environmental flows are usually unavailable to extract as a resource. Therefore, focus is on the intermediate flow region, which represents the water that can be harnessed for various uses.

$R M S E=\sqrt{\frac{1}{N} \sum_{i=1}^{N}\left(Q_{C}-Q_{o}\right)^{2}}$

Where, $Q_{c}$ represents the stream flow computed, while $Q_{o}$, represent the observed stream flows.

\subsection{Model Development}

\subsubsection{Overview of Hydrologic Model}

The HEC-HMS model was developed for the Giriulla watershed (in Maha Oya basin) as a lumped model, with adequate representation of hydrological processes in the catchment. At this stage, selection of model components, determination of flow thresholds for evaluation, selection of calibration and verification methods were done based on the rational reasoning.

\subsubsection{Development of basin model}

The basin model was developed to represent five main components as mentioned below.

The canopy model represents the presence of vegetation in the landscape [19]; this is first filled with the fall of rainfall [15]. Simple canopy method was selected as this method is a common representation of plant canopy [20].

To exemplify surface depression storages in the ground, the surface method was adopted in the model [15], [21]. When the increased rate of rainfall beyond the rate of infiltration and after the surface storage is filled, surface runoff takes place. Literature shows that surface storage values represent the gradient of a watershed and its land use types [19].

The loss method was used in the model and for this, Deficit and constant loss method was selected. This selection was due to its simplicity and requirement of a lesser number of parameters. The parameters are, Initial Deficit, Maximum Storage and Constant Loss [16]. In addition, this method has been designed to perform continuous simulations, while other methods in the HEC HMS model are used for event-based simulations [15], [16]. A study carried out for Attanagalu Oya basin in 2013 [21] had concluded that the deficit and constant loss method performed well when compared with the SCS CN loss method. Attanagalu Oya is an adjacent catchment. To calculate the maximum storage, SCS method [16] was adopted, as it is similar to maximum potential retention (S). 
Weighted average CN values for the selected watershed were calculated by considering the antecedent moisture condition, land use types, and hydrological soil groups presented in literature [13], [17], [22], [23].

SCS Unit Hydrograph Transformation method was selected to estimate the actual surface runoff in the model since it depends on the flow length, slope of the basin, and other watershed characteristics [17], [24], [25]. Initial lag time was calculated based on the $\mathrm{Kr}$ pitch formula [10].

The recession method was selected to represent baseflow generation because this method is recommended for continuous simulations and parameter requirement is minimal [20], [24], [26]. Recession constant was initially specified based on the ratio of baseflow at the current time, to the baseflow one day earlier. Moreover, threshold type was selected as a Ratio to peak, which was selected as a parameter in this study after several trials [26].

\subsubsection{Development of Meteorological Model}

The meteorologic model was used to set up meteorological boundary settings of the model. Based on literature, Thiessen polygon method was chosen as a precipitation method to model the watershed, among seven different rainfall computation methods in HEC-HMS [15], [24], [27].

The HEC HMS model schematic of this study incorporating selected methods is given in Figure 2.

\subsubsection{Model Warm-up}

To achieve the dynamic equilibrium of hydrological models, a warm-up period is required to introduce to the model [28]. Accordingly, it was decided to use consecutive four years in a cyclic order by facilitating the model to be properly warmed up, since there was no specific number of years specified [29].

\subsubsection{Model Optimisation and Performance Evaluation}

In the HEC-HMS model, two different optimization approaches are available as stochastic and deterministic. Here deterministic optimization approach was adopted as it begins with initial parameter estimates and modify them so that the modeled results match the observed stream flow as closely as possible [19]. Accordingly, semi-automatic optimization was adopted as initial parameters were identified considering catchment characteristics as illustrated above. The MRAE (Equation 2) was used as a model performance evaluation criterion, by changing model parameters while observing visual matching of simulated and measured flow hydrographs.

$$
M R A E=\frac{1}{N} \sum_{i=1}^{N} \frac{\left|Q_{C}-Q_{O}\right|}{Q_{O}}
$$

Further, several calibration trials were carried out to obtain good performance in the model and it was evaluated graphically and numerically with the use of performance indicators, including total hydrograph (in semi-log), annual water balance, Low (L), Medium (M), and High (H) flows in Flow Duration Curve (FDC).

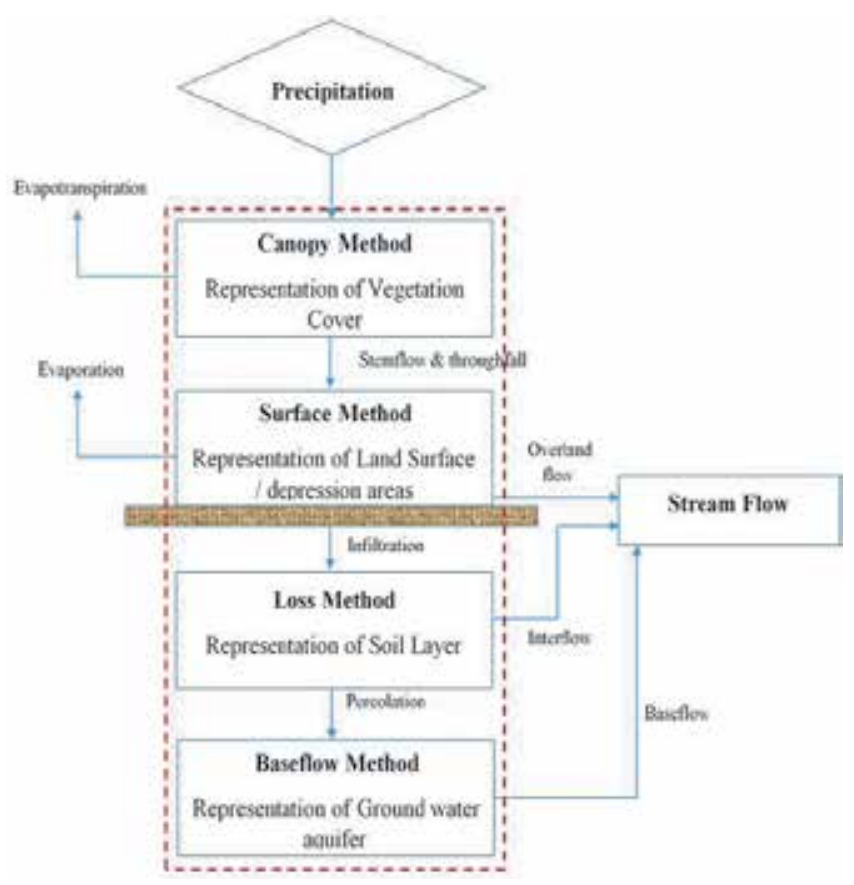

Figure 2 - Schematic Diagram of the Model

\subsubsection{Flow Threshold Cassification}

A comprehensive literature review revealed that many studies considered high and low flow zones are centered at the $5^{\text {th }}$ and $95^{\text {th }}$ percentiles, respectively [30], [31]. However, methodology used in the study carried out by Wijesekara in 2018 [32] was adopted in this study to determine the high and low flow thresholds. Accordingly, low and high flow boundaries for Giriulla were approximately $11 \%$ and $83 \%$, respectively.

\section{Results}

\subsection{Model Calibration and Validation}

Summary of statistical performance of calibration and validation results are shown in Table 1 for the Giriulla watersheds. Further, Figure 3 and Figure 4 illustrate the FDC for calibration and validation, respectively. Based on the model results, they show good performance for both high and medium flows in both calibration and 
verification period while showing a low degree of matching during low flow estimation.

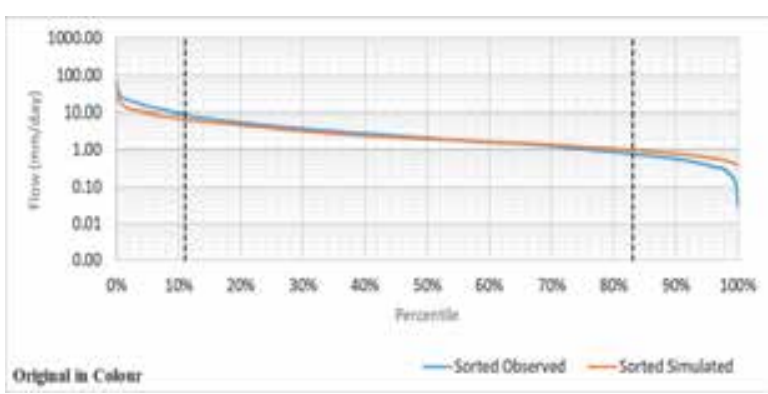

Figure 3 - Flow Duration Curve in Giriulla Calibration

Table 1 - Model Performance Indicators

\begin{tabular}{|l|c|c|c|c|}
\hline \multirow{5}{*}{$\begin{array}{c}\text { Giriulla } \\
\text { Gauging } \\
\text { Station }\end{array}$} & \multicolumn{5}{|c|}{ Flow Duration Curve } \\
\cline { 2 - 5 } & ALL & H & M & L \\
\hline Calibration & 0.24 & 0.32 & 0.13 & 0.66 \\
\hline MRAE (Sorted) & 0.24 & 6.71 & 0.62 & 0.06 \\
\hline RMSE (Sorted) & 2.24 & \\
\hline Validation & & & \\
\hline MRAE (Sorted) & 0.18 & 0.22 & 0.15 & 0.30 \\
\hline RMSE (Sorted) & 1.45 & 4.37 & 0.36 & 0.17 \\
\hline
\end{tabular}

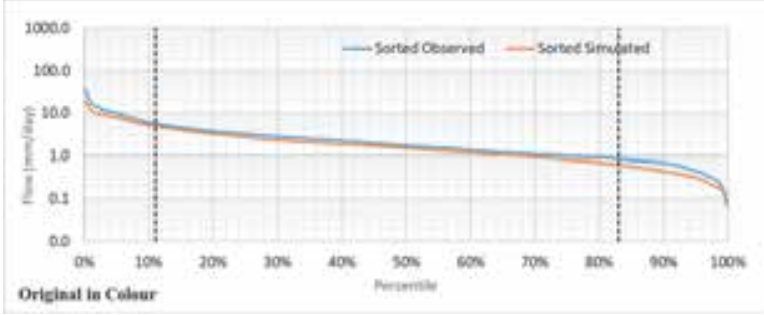

Figure 4 - Flow Duration Curve in Giriulla Validation

Further, annual water balance and seasonal water balance were checked for both calibration and validation periods. AWB analysis shows the annual average water balance error for the Giriulla watershed. Accordingly, it shows a 19\% of error increase in the calibration period, while showing a $20 \%$ error increase in the validation period as well.

Figure 5 and Figure 6 illustrate the variation in graphically. Similarly, seasonal water balance errors are overestimated by $23 \%$ (Maha) and 10\% (Yala) for calibration, while indicating a $23 \%$
(Maha) and a 17\% (Yala) increase for the validation period.

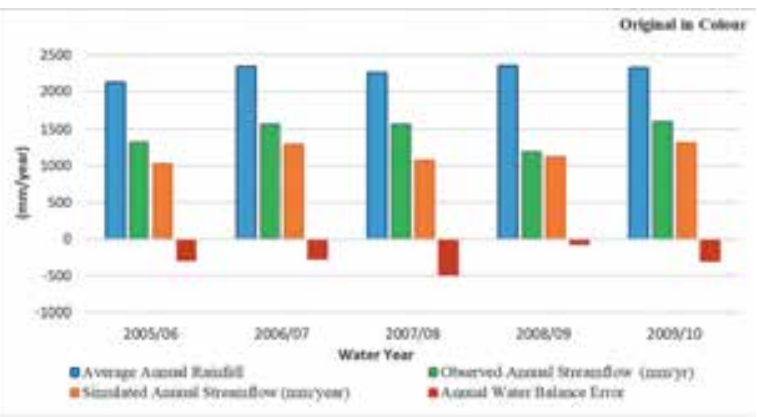

Figure 5 - Annual Water Balance - Calibration

When the model response concerning time of occurrences and flood peak matching was considered, it indicated good agreement between observed flows and estimated flows. Figure 7 and Figure 8 show sample flow hydrographs for calibration and validation, respectively. According to Table 1, MRAE for high flows for calibration was 0.32, while same for the validation was 0.22 .

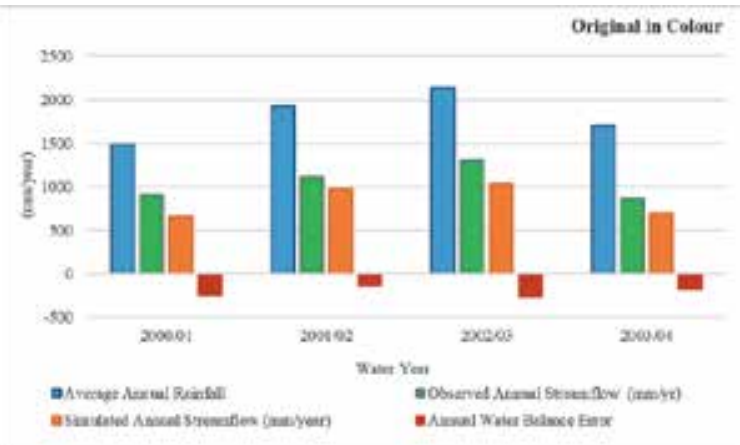

Figure 6 - Annual Water Balance - Validation

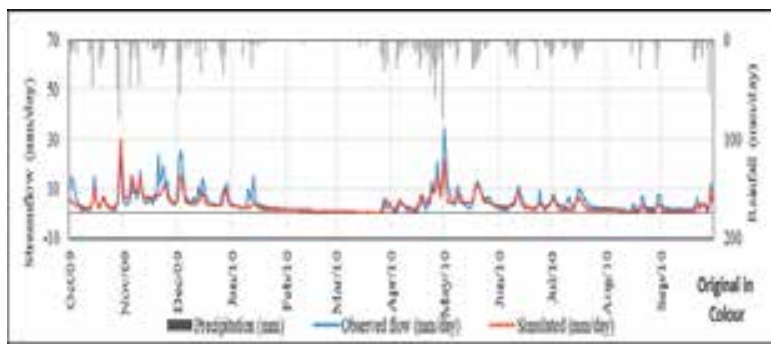

Figure 7 - Flow Hydrograph for the Calibration Period (2009/2010)

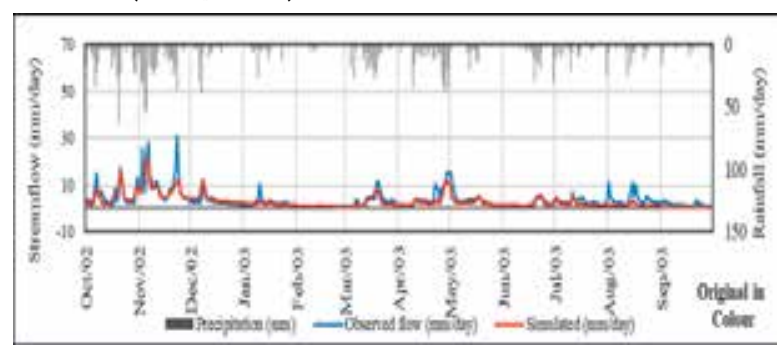

Figure 8 - Flow Hydrograph for the Validation Period (2002/2003) 


\subsection{Optimized Model Parameters}

After systematic calibration and validation trials, the most promising set of parameters were identified (Table 2).

Table 2 - Optimized Model Parameters

\begin{tabular}{|l|r|}
\hline \multicolumn{1}{|c|}{ Parameter } & \multicolumn{1}{|c|}{$\begin{array}{c}\text { Optimised } \\
\text { Parameters }\end{array}$} \\
\hline $\begin{array}{l}\text { Recession - } \\
\text { Initial Discharge }\left(\mathrm{m}^{3} / \mathrm{s}\right)\end{array}$ & 25.00 \\
\hline $\begin{array}{l}\text { Recession - } \\
\text { Ratio to Peak }\end{array}$ & 0.22 \\
\hline $\begin{array}{l}\text { Recession - } \\
\text { Recession Constant }\end{array}$ & 0.98 \\
\hline $\begin{array}{l}\text { SCS Unit Hydrograph - } \\
\text { Lag Time (min) }\end{array}$ & 991.10 \\
\hline $\begin{array}{l}\text { Simple Canopy - } \\
\text { Initial Storage (\%) }\end{array}$ & 2.24 \\
\hline $\begin{array}{l}\text { Simple Canopy - } \\
\text { Max Storage (mm) }\end{array}$ & 25.00 \\
\hline $\begin{array}{l}\text { Simple Surface - } \\
\text { Initial Storage (\%) }\end{array}$ & 1.98 \\
\hline $\begin{array}{l}\text { Simple Surface - } \\
\text { Max Storage (mm) }\end{array}$ & 35.34 \\
\hline $\begin{array}{l}\text { Deficit and Constant - } \\
\text { Constant Rate (mm/hr) }\end{array}$ & 1.15 \\
\hline $\begin{array}{l}\text { Deficit and Constant - } \\
\text { Initial Deficit (mm) }\end{array}$ & 24.63 \\
\hline $\begin{array}{l}\text { Deficit and Constant - } \\
\text { Maximum Deficit (mm) }\end{array}$ & 65.52 \\
\hline
\end{tabular}

\section{Discussion}

\subsection{Selection of Station and Data}

Based on the extensive literature survey, it was found that consideration of data selection strategies are very important, including the availability of long series of daily data, representative hydrological variability such as mean and extreme (drought and flood), and maximum spatial-temporal data density [33]. Further, it was recognized that the availability of five to ten years of continuous data series is adequate to effectively develop a daily lumped hydrological model with the representation of catchment processes [16].

When considering the hydrometric stations established in the Maha Oya basin, only two stations are functioning well, which are Giriulla gauging station and the Badalgama gauging station. After analysing the available data, the Giriulla gauging station was selected for this study. Accordingly, for the Giriulla gauging station, $2005 / 2006$ to $2009 / 2010$ period was selected as calibration period, while 2000/2001 to $2004 / 2005$ was selected as verification period, since data availability was much better than with compared to most recent period. Station density is a very important factor [11] and with the consideration of this as a key factor, six rainfall stations were selected with good spatial distribution and greater than $10 \%$ raw data availability.

\subsection{Model Simulation and Optimisation}

HEC-HMS model has introduced two optimization methods as deterministic and stochastic. Deterministic optimization has been chosen to use in this study since this optimization method facilitates, to begin with, the initial parameters and change them. Accordingly, it will be searched for the best parameter set, which minimizes the difference between the simulated streamflow series vs observed streamflow series [19]. During the process of parameter optimization, it was essentially required to ensure, unrealistic parameters were not used.

However, before proceeding with a semiautomatic approach, a fully automatic approach was also tested, but it was not able to converge the model to optimize the parameters while discontinuing the model with local minimum. Further, manual calibration method was not used, since it was highly time-consuming.

\subsection{Model Performance Evaluation}

To assess model performance, both statistical and graphical model assessment techniques were used in this study, as mentioned in the previous sections. The model evaluation statistics, Mean Ratio Absolute Error (MRAE) was used. This was used as it indicates the sum of residual error relative to the magnitude of the measured streamflow at each point of observation. In addition to that, it supports to facilitate the water resources planning and management.

Further, as a graphical model performance evaluation, combined hydrographs of the HECHMS model, simulated streamflow, and daily observed streamflow were plotted against daily average precipitation. Visual checking of hydrographs was performed for each of the water year, which includes both calibration and validation periods. Moreover, a comparison of flow hydrographs provided an overall idea of the behaviour of low and high flow magnitude variation over time, and occurrence of actual events and simulated events. According to the numerical and visual observations, the developed HEC-HMS model showed good performance concerning the observed flows. 


\subsection{Model Calibration and Validation}

The key objective of the hydrological model calibration was to optimize the difference between observed flows and simulated flows, including high flows, low flows, and timing, while identifying the best set of model parameters. During periods of calibration and validation, extreme events such as floods and droughts were included, by enabling the model to be exited.

The MRAE and RMSE values for the entire sorted flow regimes at Giriulla are 0.24 and 2.24 $\mathrm{mm} /$ day for the calibration period, and the same for the validation period are 0.18 and 1.45 $\mathrm{mm} /$ day, respectively.

Further, when considering the visual checking of annual hydrographs at Giriulla, time of occurrence was at an acceptable level, and it was revealed that model response with wet conditions was high compared to dry conditions. Instead of one layer loss model, the five-layer Soil Moisture Accounting (SMA) Loss model shall provide good performance in low flow simulation. However, the main objective of the study was to facilitate water resources management and planning, hence the performance of the FDC is very important. Based on the FDC, the HEC-HMS model showed a good match between simulated and observed flows, by enabling application of this model in water resources management activities in Maha Oya Basin.

\subsection{Water Resources Management}

As discussed above, model performance in high and medium flow estimation showed better agreement, and it is very important in water resources management. Further, seasonal water balance is also very important for water management and, based on the model results, it also showed an acceptable level of accuracy.

\section{Conclusions}

1. HEC-HMS model was successfully developed for the Giriulla Watershed in Maha Oya Basin with good accuracy having MRAE values of 0.24 and 0.18 for calibration and validation, respectively.

2. Developed HEC-HMS hydrological model for the Giriulla watershed can be used to simulate streamflow with approximately $75 \%-80 \%$ of overall accuracy for water resources management activities.

3. The model can reproduce the high and medium flows at a good confidence level, such as $73 \%$ for high flows and $86 \%$ for medium flows.

4. Annual water balance error at the Giriulla was overestimated by $20 \%$, while indicating seasonal water balance errors are overestimated, 23\% (Maha) and 17\% (Yala).

5. Due to low performance in low flow estimation, this model cannot be used for environmental flow management in daily timescale.

\section{Acknowledgement}

The support, motivation and immense knowledge received by the contributions of Late Shri Madanjeet Singh, the South Asia Foundation, and the University of Moratuwa, enabling this study which was carried out as part of the requirement for a master's degree completed at the Department of Civil Engineering of University of Moratuwa, Sri Lanka, is gratefully acknowledged. Further, Project Director (CRIP), Deputy Project Director (CRIP-DBIP) and staff are appreciated and extend my honest thanks for providing me an opportunity and support to carry out this research.

\section{References}

1. Abu-Zeid, M. and Shiklomanov, I. A. Water Resources as a Challenge of the Twenty-First Century, no. 959. 2004.

2. Trenberth, K. E. "Climate and Climate Change: Intergovernmental Panel on Climate Change," Encycl. Atmos. Sci. Second Ed., pp. 90-94, 2015, doi: 10.1016/B978-0-12-382225-3.00492-8.

3. Loucks, D. P. "Sustainable Water Resources Management," Water Int., vol. 25, no. 1, pp. 3-10, 2000, doi: 10.1080/02508060008686793.

4. Devia, G. K, Ganasri, B. P, and Dwarakish, G. S “A Review on Hydrological Models," Aquat. Procedia, vol. 4, pp. 1001-1007, Oct. 2015, doi: 10.1016/j.aqpro.2015.02.126.

5. Sampath, D. S, Weerakoon, S. B, and Herath, S, "HEC-HMS Model for Runoff Simulation in a Tropical Catchment with Intra-Basin DiversionsCase Study of the Deduru Oya River Basin, Sri Lanka," ENGINEER 2015.

6. Ponrajah, A. J. P, "Design of Irrigation Headworks for Small Catchments (2nd ed.)." Irrigation Department, 1984.

7. Mouelhi, S, Michel, C, Perrin, C, and Andréassian $\mathrm{V}$, "Stepwise Development of a Two-parameter Monthly Water Balance Model," J. Hydrol., vol. 
318, no. 1-4, pp. 200-214, 2006, doi: 10.1016/j.jhydrol.2005.06.014.

8. Xu, C. Y. and Singh, V. P. "A Review on Monthly Water Balance Models for Water Resources Investigations," Water Resour. Manag., vol. 12, no. 1, pp. 31-50, 1998, doi: 10.1023/A:1007916816469.

9. Sugawara, M. Watanabe, I. Ozaki E. and Katsuyama, Y. "Tank Model with Snow Component : Research Notes of the National Research Center for Disaster Prevention," 1984, vol. No.65, p. 293.

10. Chow, L. W. Maidment, V. Te, Mays, D. R. "Applied Hydrology". McGraw-Hill, Inc, 1988.

11. Kodippili, T. "Influence of Station Density and Interpolation Methods on Spatial Averaging of Rainfall for Influence of Station Density and Interpolation Methods on Spatial Averaging of Rainfall for," no. May, 2019.

12. Teegavarapu, R. S. V. and Chandramouli, V. "Improved Weighting Methods, Deterministic and Stochastic Data-driven Models for Estimation of Missing Precipitation Records," J. Hydrol., vol. 312, no. 1-4, pp. 191-206, 2005, doi: 10.1016/j.jhydrol.2005.02.015.

13. Jayadeera, P. M. “Development of a Rainfall Runoff Model for Kalu Ganga Basin of Sri Lanka using HEC_HMS model," Sri Lanka, p. 205, 2016.

14. Garcia, F. Folton, N. and Oudin, L. "Which Objective Function to Calibrate RainfallRunoff Models for low-flow Index simulations?," Hydrol. Sci. J., vol. 62, no. 7, pp. 1149-1166, 2017, doi: 10.1080/02626667.2017.1308511.

15. De Silva, M. M. G. T. Weerakoon, S. B. and Herath, S. "Modeling of Event and Continuous Flow Hydrographs with HECHMS: Case study in the Kelani River basin, Sri Lanka," J. Hydrol. Eng., vol. 19, no. 4, pp. 800-806, 2014, doi: 10.1061/(ASCE)HE.19435584.0000846

16. Halwatura, D. et al., "Application of the HEC-HMS Model for Runoff Simulation in a Tropical Catchment," Environ. Model. Softw., vol. 46, no. 1, pp. 155-162, Oct. 2013, doi: 10.1016/j.envsoft.2013.03.006.

17. Verma, A. K. Jha, M. K. and Mahana, R. K. "Evaluation of HEC-HMS and WEPP for Simulating Watershed Runoff using Remote Sensing and Geographical Information System," Paddy Water Environ., vol. 8, no. 2, pp. 131-144, 2010, doi: 10.1007/s10333-0090192-8.
18. Ouédraogo, W. A. A. Raude, J. M. and Gathenya, J. M. "Continuous Modeling of the Mkurumudzi River Catchment in Kenya using the HEC-HMS Conceptual Model: Calibration, Validation, Model Performance Evaluation and Sensitivity Analysis," Hydrology, vol. 5, no. 3, 2018, doi: $10.3390 /$ hydrology 5030044 .

19. Scharffenberg, B. Bartles, G. K. Brauer, M. Fleming, T. "Hydrologic Modeling System User's Manual," 2018.

20. Sok, K. and Oeurng, C. "Application of HECHMS Model to Assess Streamflow and Water Resources Availability in Stung Sangker Catchment of Mekong' Tonle Sap Lake Basin in Cambodia," no. December, pp. 1-16, 2016, doi: 10.20944/preprints201612.0136.v1.

21. Halwatura, D. and Najim, M. M. M. "Application of the HEC-HMS model for Runoff Simulation in a Tropical Catchment," Environ. Model. Softw., vol. 46, pp. 155-162, Oct. 2013, doi: 10.1016/j.envsoft.2013.03.006.

22. “Part 630 Hydrology National Engineering Handbook Chapter 9, Hydrologic Soil-Cover Complexes" 2004.

23. Ali, M. Khan, S. J. Aslam, I. and Khan, Z. "Simulation of the Impacts of Land-use Change on Surface Runoff of Lai Nullah Basin in Islamabad, Pakistan," Landsc. Urban Plan., vol. 102, no. 4, pp. 271-279, 2011, doi: 10.1016/j.landurbplan.2011.05.006.

24. Paper, O. "Rainfall-runoff Modelling of Doddahalla Watershed - An Application of HEC-HMS and SCN-CN in Ungauged Agricultural Watershed," pp. 1-16, 2016, doi: 10.1007/s12517-015-2228-2.

25. Sampath, D. S. Weerakoon, S. B. and Herath, S. "HEC-HMS Model for Runoff Simulation in a Tropical Catchment with Intra-basin Diversions - Case Study of the Deduru Oya River Basin, Sri Lanka," Eng. J. Inst. Eng. Sri Lanka, vol. 48, no. 1, p. 1, Oct. 2015, doi: 10.4038/engineer.v48i1.6843.

26. Kamran, M. "Effect of Watershed Subdivision and Antecedent Moisture Condition on HEC-HMS Model Performance in the Maha Oya Basin, sri lanka," SRI LANKA, p. 202, 2017.

27. Daggupati, P. et al., "A Recommended Calibration and Validation Strategy for Hydrologic and Water Quality Models," Trans. ASABE, vol. 58, no. 6, pp. 1705-1719, 2015, doi: 10.13031/trans.58.10712. 
28. Jayadeera, P. M. and Wijesekera, N. T. S. “A Diagnostic Application of HEC- HMS Model to Evaluate the Potential for Water Management in the Ratnapura Watershed of Kalu Ganga Sri Lanka," Eng. J. Inst. Eng. Sri Lanka, vol. 52, no. 3, p. 11, 2019, doi: 10.4038/engineer.v52i3.7361.

29. EPA, “An Approach for Using Load Duration Curves in the Development of TMDLs," U.S. Environ. Prot. Agency, p. 68, 2007.

30. Li-Juan Li, D. Y. Q. Lu Zhang, Hao Wang, Juan Wang, Jun-Wei Yang, De-Juan Jiang, JiuYi Li, "Advanced Bash-Scripting Guide An in-depth Exploration of the Art of Shell Scripting Table of Contents," Wiley Intersci., vol. 2274, no. November 2008, pp. 2267-2274, 2007, doi: 10.1002/hyp.

31. Wijesekera, N. T. S. "Classification of Streamflow Observations for Water Management," no. February, 2018, doi: 10.13140/RG.2.2.23605.58089.

32. Cunderlik, J. and Simonvic, S. P. "Calibration, Verification and Sensitivity Analysis of the HEC-HMS Hydrologic Model," J. Chem. Inf. Model., vol. 53, no. 9, pp. 1689-1699, 2004, doi: 10.1017/CBO9781107415324.004. 